\title{
20. COMPARISON OF NATURAL GAMMA RAY ACTIVITY PROFILES FROM DOWNHOLE LOGGING AND THE MST CORE LOGGER AT SITE 911 (YERMAK PLATEAU) ${ }^{1}$
}

\author{
Mitchell Lyle, ${ }^{2}$ James Bristow, ${ }^{3}$ Jan Bloemendal, ${ }^{4}$ and Frank R. Rack ${ }^{5}$
}

\begin{abstract}
The newly installed multisensor track (MST) natural gamma ray activity spectrometer should provide a powerful way to correlate between recovered cores and logging data. We evaluate its use for this purpose at Ocean Drilling Project Site 911 on the Yermak Plateau, in which $500 \mathrm{~m}$ of silty clays and clayey silts were recovered. We found that significant corrections need to be made to the MST natural gamma ray activity data before profiles can be constructed. The important corrections are for background, porosity, voids, and cracks, and for an inefficient detector geometry. With these corrections, however, a good match between the MST profile and the logging data can be made. The logging profile can then be used to assign depths and identify gaps in the section of the hole cored by the extended core barrel (XCB). We also tried to use the MST natural gamma ray activity data to calculate potassium (K) contents of Site 911 sediments, but failed to establish any correlation between K contents of the clays measured by X-ray fluorescence spectrometer (XRF) and the K-specific gamma ray activity. We believe that this is primarily a problem of detector sensitivity and the relatively small range of variation of K contents in Site 911 sediments.
\end{abstract}

\section{INTRODUCTION}

Measurement of natural gamma ray activity is a simple and powerful method to remotely sense lithology of geological formations. Profiles of natural gamma ray activity from downhole well logging have been used for decades to evaluate lithology. The natural gamma ray activity logs have proven very reliable and repeatable. Potentially, natural gamma ray activity measurements are important for correlating between core recovered by the Ocean Drilling Project (ODP) and well logging profiles taken in the drillholes. Natural gamma ray activity on a weight basis is unaffected by subtle damage to the recovered core by drilling and is only affected by changing the $\mathrm{K}, \mathrm{U}$, and/or Th content of the solid material. Density or velocity measurements on core, in contrast, can be altered significantly by small degrees of decompression or stirring.

The technology to measure natural gamma ray activity on recovered core has only recently been added to the standard suite of measurements made by the Ocean Drilling Program on recovered cores (Hoppie et al., 1994). Natural gamma ray activity is now measured routinely by the MST (multisensor track) also used to measure profiles of $P$-wave velocity, GRAPE (Gamma Ray Attenuation Porosity Evaluator) wet bulk density, and magnetic susceptibility on ODP core sections. In this paper we evaluate this technology for use in a fine-grained clay sequence, specifically that of ODP Site 911 on the Yermak Plateau.

Thiede, J., Myhre, A.M., Firth, J.V., Johnson, G.L., and Ruddiman, W.F. (Eds.) 1996. Proc. ODP, Sci. Results, 151: College Station, TX (Ocean Drilling Program).

${ }^{2}$ Center for Geophysical Investigation of the Shallow Subsurface, Boise State University, Boise, Idaho 83725 , U.S.A. mlyle@ cgiss.idbsu.edu

${ }^{3}$ Borehole Research, Department of Geology, University of Leicester, Leicester LEI 7RH, United Kingdom.

${ }^{4}$ Department of Geology, University of Liverpool, P.O. Box 147, Liverpool L69 3BX, United Kingdom.

s'Ocean Mapping Group, Department of Surveying Engineering, University of New Brunswick, P.O. Box 4400, Fredericton, New Brunswick E3B 5A3, Canada.

\section{Overview}

Sediments and rocks have gamma ray activity because most contain at least some of the naturally occurring isotopes of potassium, uranium, and thorium. ${ }^{40} \mathrm{~K}$ decays to ${ }^{40} \mathrm{Ar}$ while releasing a gamma ray of a specific energy $(1.46 \mathrm{MeV}) .{ }^{238} \mathrm{U},{ }^{235} \mathrm{U}$, and ${ }^{232} \mathrm{Th}$ all decay through a series of daughter nuclides before they decay to their stable lead isotopes. Many of the radioactive daughters in these chains also produce characteristic gamma rays as they decay. These gamma ray energies can be monitored to estimate the amount of uranium and thorium in the original sample. As the characteristic gamma rays are scattered by interactions with other atoms, they lose energy and produced a lower-energy "hump" of gamma ray activity which can not be used to distinguish specific isotopes. The gamma ray "hump" contains the bulk of the natural gamma ray activity in a typical sediment sample but is non-diagnostic for elemental determinations.

Typically two types of natural gamma ray activity measurements are made: (1) a total count of natural gamma ray activity in an energy range from about $150 \mathrm{KeV}$ to $3 \mathrm{MeV}$, and (2) specific windows set to encompass characteristic gamma rays from $\mathrm{K}, \mathrm{U}$, and $\mathrm{Th}$. The first type of measurement is of the total radioactivity of the formation and includes the nondiagnostic gamma ray activity, while the second type of measurement can be used to measure $\mathrm{K}, \mathrm{U}$, and Th contents in the sample.

In this paper we develop techniques to correct, calibrate, and convert MST data to dpm (disintegrations per minute) per gram of dry sediment. We also evaluate whether the MST natural gamma ray sensor is sufficiently sensitive to measure the relatively low variations in potassium observed in Leg 151 clays. Finally, we build a composite natural gamma ray activity profile at Site 911 from the well logging and MST data.

\section{Site 911}

Site 911 is the northernmost drill site occupied on Leg 151. It is located on the shallow southern part of the Yermak Plateau, which is covered with thick sequence of Neogene sediments. $506 \mathrm{~m}$ of Pliocene- to Quaternary-age clays and clayey silts were drilled here. From a paleomagnetic age of $2.6 \mathrm{Ma}$ at a depth of $360 \mathrm{mbsf}$ (Ship- 
board Scientific Party, 1995), the average sedimentation rate is about $140 \mathrm{~m} / \mathrm{m} . \mathrm{y}$. Consequently, if climate caused a change in sedimentary properties, Milankovitch orbital cycles should appear as wavelengths of around 2.7-3.2 m (precession), $5.7 \mathrm{~m}$ (tilt), and $14 \mathrm{~m}$ (eccentricity).

\section{CONVERSION OF RAW MST DATA INTO NATURAL GAMMA RAY ACTIVITY PROFILES}

It is important to remember that significant corrections must be made to both well logging and MST profiles of natural gamma activity before the two data sets can be reliably compared. Ideally, both data sets should be converted from the measured natural gamma ray activity per volume of material to the desired natural gamma activity on a mass basis (per gram of dry sediment).

\section{Well-Logging Data}

Well logs should be corrected for porosity of the formation (estimated from a density $\log$ ), and for the width of the borehole. Void space has no natural gamma ray activity, and a formation of high porosity will have a smaller gamma ray activity than one with low porosity, even if they are composed of the same material. In addition, because gamma rays are absorbed over distance, hole width can affect the raw natural gamma ray activity (Fig. 1). Moving the gamma ray source away from the detector lowers the raw counts; changes in the width of the drill hole effectively move the source (the sediments) away from or toward the detector and produce erroneous raw data. IIlustrated in Figure 1 is a section of borehole in Hole 911A, where two swelling clay intervals were encountered during logging. The swelling of the clays shrank the borehole diameter from the 11 -1/2-in $(29.2$ $\mathrm{cm}$ ) gauge to about 5 in $(12.7 \mathrm{~cm})$ at about $350-355 \mathrm{mbsf}$ and $375-$ 390 mbsf. High raw counts in these two intervals were from the proximity of the sediment formation. When corrected for borehole diameter, the peaks in natural gamma ray activity disappear.

Typically, total natural gamma ray activity (SGR) profiles are not corrected for porosity and are expressed in API (American Petroleum Institute) units, a semiquantitative standard based upon the logging tool response in a standard test well (1 API unit equals 1/200 of the

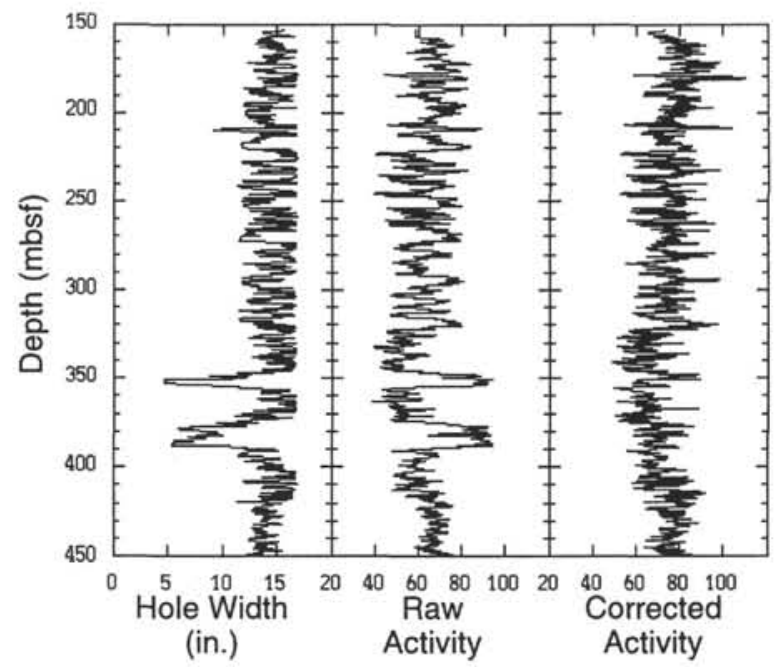

Figure 1. Effect of hole width upon raw natural gamma activity measured by the NGT logging tool. Because gamma rays are absorbed with distance and the logging tool is roughly centered in the borehole, a wide borehole will have lower raw counts than a narrow one in homogeneous sediments. Two constrictions in Hole 911A appear as peaks in raw counts $(-350 \mathrm{mbsf}$, and 375-390 mbsf). When corrected for borehole diameter, the peaks disappear. deflection between the high and low activity units in the test well; Keys and MacCary, 1971; Hoppie et al., 1994). A linear correction factor can be generated to convert API units to disintegrations per minute. This correction factor takes into account tool efficiency and detector offset distance.

\section{MST Data}

Three levels of correction must be made to the MST data in order to convert raw counts to a calibrated $\mathrm{dpm} / \mathrm{g}$ profile:

1. Background gamma ray activity from the surroundings must be subtracted from the total.

2. The mass of dry sediment within the detector window must be calculated.

3. A sample with a known gamma ray activity must be used to calculate the detector efficiency to convert from raw counts to known natural gamma ray activity.

\section{Background Correction}

The detector background was measured by putting an empty tray into the MST and measuring the natural gamma activity. For five measurements of $30 \mathrm{sec}$, the background was $13.4 \pm 0.24$ disintegrations/sec, while for five measurements of $15 \mathrm{sec}$ the background measured was $13.0 \pm 0.73$ disintegrations $/ \mathrm{sec}$. Spot checks throughout the cruise yielded the same background activity.

\section{Mass of Sediment Within Detector Window}

The natural gamma ray activity measured by the detector depends upon the effective mass of sediment within the detector sensing region and its natural radioactivity. The effective mass is a combination of the detector's ability to sense gamma rays from a particular depth interval within the measurement region and the dry mass of sediment there. Sediments at a distance from the detector but still within the measurement region will contribute counts to the total measured natural gamma ray activity. Figure 2 is the activity curve resulting from

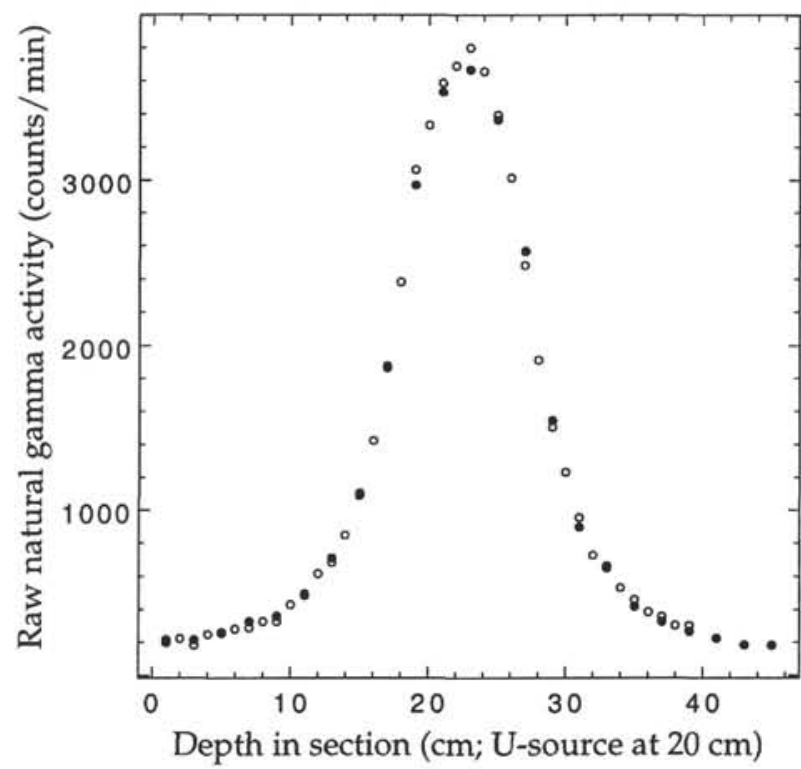

Figure 2. Depth resolution of the MST natural gamma detectors revealed by passing a point uranium source through the detector. Two repeat passes are shown. The activity curve is almost a perfect gaussian distribution and was used to correct MST gamma ray activity for voids and changes in porosity. See text for details. 
passing a point source uranium sample through the detector. The detector responds to natural gamma ray activity in sediments well away from a position directly under the detector. Depth resolution of the MST sensor, estimated from the peak width at half height, is $\pm 6 \mathrm{~cm}$. The relatively low depth resolution of the detector means that measurement intervals should be spaced at least $10 \mathrm{~cm}$ apart to optimize both resolution and efficiency. On Leg 151, natural gamma ray activity measurements were spaced at $20 \mathrm{~cm}$. In addition, the low depth resolution of the detector means that the raw natural gamma activity will be sensitive to voids near the measured interval.

We developed a procedure to correct for voids and porosity within the measurement region of the detector. At each depth in the core where a GRAPE measurement was taken we estimated void space (naturally-occurring porosity as well as coring disturbance) and corrected the sediment profile to a constant mass underneath the gamma ray detector. With correction factors for the sediment mass variation with depth and the variation of detector response as a function of distance from the measurement site (Fig. 2) we could correct the activity for sediment heterogeneities and coring faults. One further correction for detector geometry (see next section) then converts the data to $\mathrm{dpm} / \mathrm{g}$ of dry sediment.

To correct for voids we assumed that the typical grain density of site 911 sediments is $2.71 \mathrm{~g} / \mathrm{cm}^{3}$ and that any porosity greater than $75 \%$ (any wet bulk density less than $1.4463 \mathrm{~g} / \mathrm{cm}^{3}$ ) represented a region with some void space. These values were chosen based upon inspection of the index physical properties at Site 911 (Shipboard Scientific Party, 1995). In more heterogeneous sediments, one should use the grain density profile from shipboard physical properties data to vary the grain density with depth in the hole. The cutoff porosity to distinguish a void also will depend on the sediment type.

Where porosity was greater than $75 \%$, the void criterion, we calculated the volume of empty space by assuming the sediment/porewater mixture had a constant porosity of $75 \%$. All other variations in bulk density were then caused by mixing this slurry with air. The technique was excellent at locating cracks and gas voids in Site 911 cores. The result of the above procedure is a dry bulk density profile (mass of dry sediment/volume of original sediment). By normalizing the dry bulk density profile to a constant dry bulk density (here we used $1 \mathrm{~g} / \mathrm{cm}^{3}$ ) we calculated correction factors against depth to correct the natural gamma activity for void and porosity variation.

We corrected for the variation of detector response as a function of distance from the measurement depth by fitting the detector response shown in Figure 2 with a gaussian function:

$$
\left.N_{z} / N_{\text {tot }}=0.1584 \mathrm{e}^{-1 / 2}\left(\left(Z-Z_{0}\right) / 5\right)^{2}\right)
$$

where $N_{z} / N_{\text {fot }}$ is the fraction of total counts emanating from an inter$\mathrm{val}$ a distance of $\left(\mathrm{Z}-\mathrm{Z}_{0}\right)$ from the detector. The denominator 5 represents the standard deviation of activity with depth for this detector.

Natural gamma ray activity could now be corrected for voids by assuming that the core is chemically homogeneous within the measurement region. Expected counts for each depth interval $Z$ within the measurement region are thus the total counts $\left(N_{t o t}\right) \times$ the right-hand side of the equation evaluated at $\left(Z-Z_{o}\right)$. This number was multiplied by the mass correction factor and then summed over the measurement region to correct the counts for voids. In practice, intervals with large amounts of void space were not corrected accurately, so we eliminated natural gamma ray activity measurements in which the dry bulk density weighted by the same gaussian function was less than $0.6 \mathrm{~g} /$ $\mathrm{cm}^{3}$.

\section{Calibration of the Detector}

The corrections to this point have taken care of background and for voids and porosity. A final correction must be made for detector geometry and efficiency. For the maximum count rate a natural gam- ma detector should surround the sample to receive all gamma rays, since they are emitted without a preferred direction. The natural gamma ray detector on the JOIDES Resolution instead is made up of four $\mathrm{NaI}$ crystals at right angles around the core (Fig. 3). Only a small portion of the emitted gamma rays intersect the detector. In addition, not all gamma rays that pass through the detector cause a count. The detector has an efficiency with which it detects radioactive disintegrations.

The detector was calibrated by using the $\mathrm{KCl}$ standard also used to calibrate the GRAPE density detector. This standard consists of an ODP standard core filled with $\mathrm{KCl}$ and has a known mass of the gamma-emitting element, potassium. Based upon the density of $\mathrm{KCl}$ $\left(1.98 \mathrm{~g} / \mathrm{cm}^{3}\right)$ and the atomic masses of $\mathrm{K}$ and $\mathrm{Cl}$, there is $1.0385 \mathrm{~g} \mathrm{~K} /$ $\mathrm{cm}^{3}$ of the standard. The natural gamma ray activity of $\mathrm{K}$ is $204 \mathrm{dpm} /$ $\mathrm{g}$ (Heier, 1969), while we measured $23.3 \mathrm{dpm} / \mathrm{g} \mathrm{K}$ on the $\mathrm{KCl}$ standard. Raw dpm/g dry sediment must thus be multiplied to 8.76 to get to a calibrated $\mathrm{dpm} / \mathrm{g}$ dry sediment.

\section{COMPARISON OF MST AND LOGGING DATA}

Figures 4 and 5 illustrate the effect of the corrections to the MST natural gamma ray activity. In Figure 4 the raw natural gamma ray activity profile from Hole $911 \mathrm{~A}$ is compared to the corrected profile. Simple inspection of the two curves reveals little similarity between the two curves, a fact borne out by the scatterplot of the two data sets (Fig. 5). There is no trend of the raw data with the corrected data, except for a consistent mean value for both data sets.

Two alternate hypotheses could explain the lack of comparison between the raw and corrected data sets: (1) the corrections to the raw

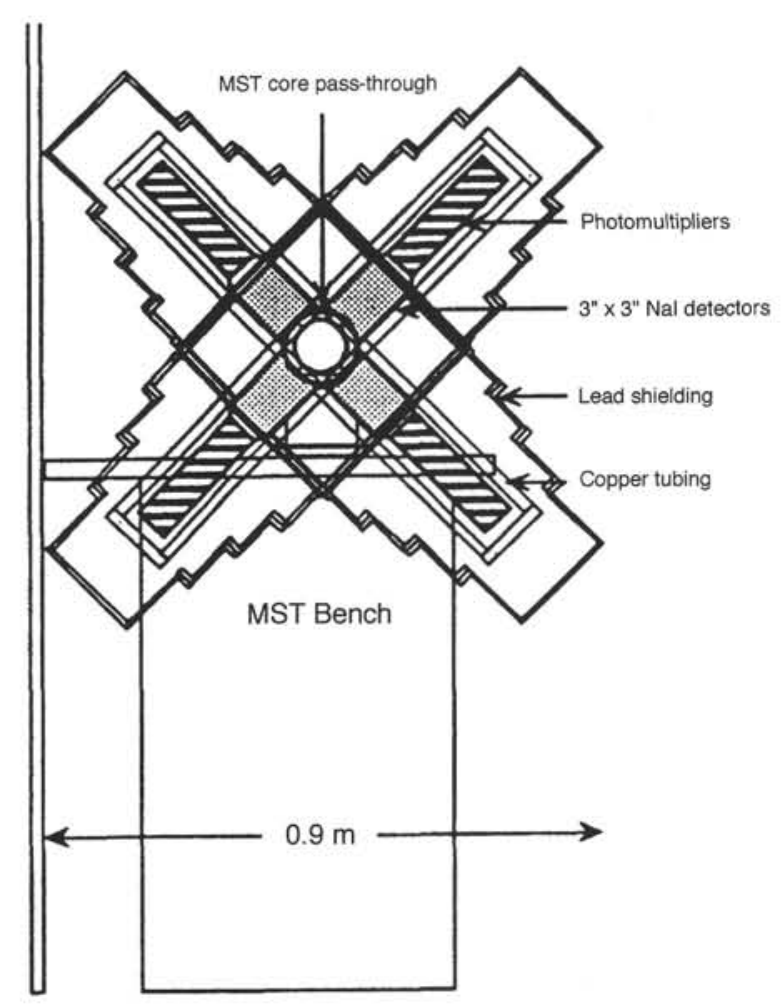

Figure 3. Cross section through the MST natural gamma ray activity sensor on the JOIDES Resolution, from Hoppie et al., 1994. Four cylindrical sodium iodide detectors are placed around the MST track, while the sediment core to be measured passes through the center of the apparatus. Because gammas are emitted in all directions, however, only a small percentage of the emitted gamma rays will be counted by the detector. 


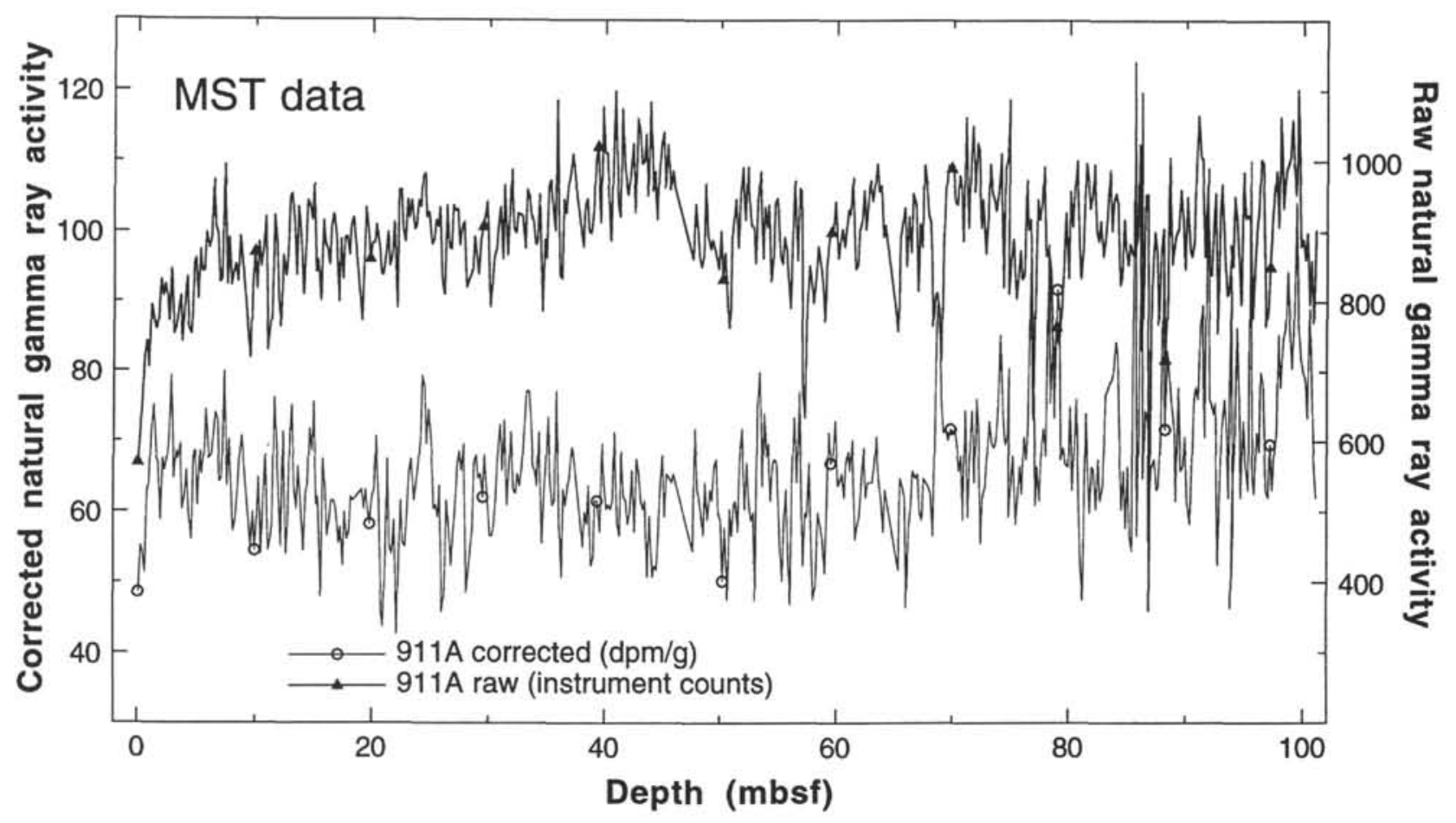

Figure 4. A comparison of raw natural gamma activity, in detector counts/sec, to corrected natural gamma ray activity in dpm/g dry sediment. The comparison interval is the first $100 \mathrm{~m}$ of Hole $911 \mathrm{~A}$. The two curves have little similarity, indicating that the correction scheme outlined in the text is needed to interpret MST natural gamma activity.

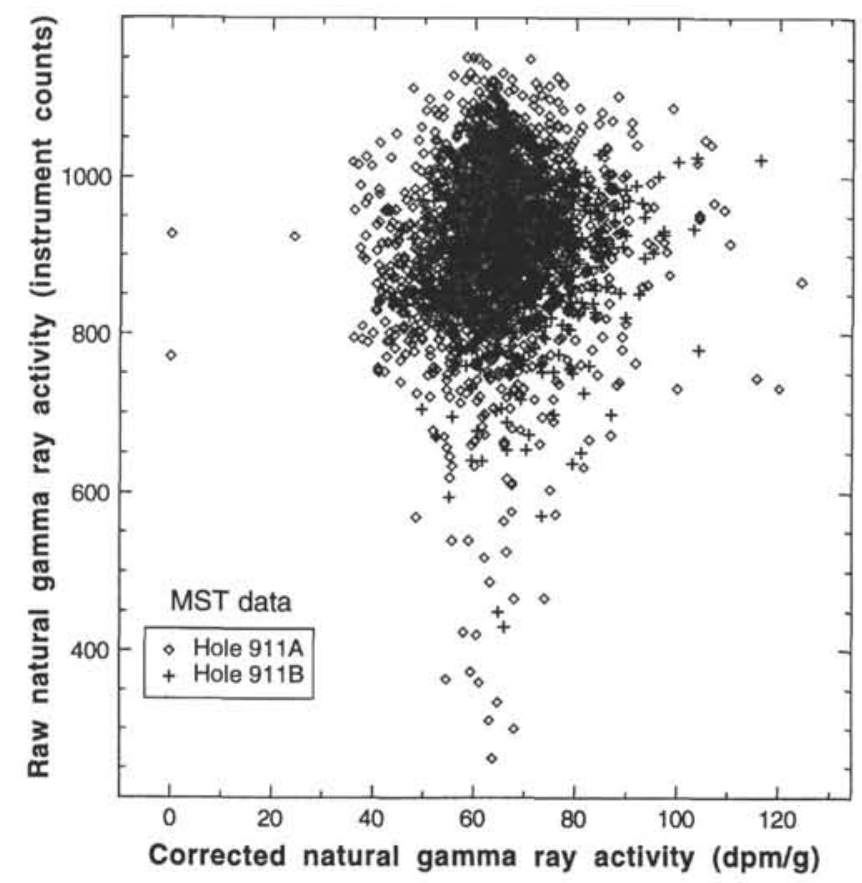

Figure 5. A scatterplot of raw natural gamma ray activity to corrected activity from the upper $100 \mathrm{~m}$ of both $911 \mathrm{~A}$ and $911 \mathrm{~B}$. Neither data set shows any systematic correlation between the raw and corrected data. data removed a significant amount of noise from the raw gamma ray activity signal by removing effects from cyclic porosity variations and random voids in the recovered core, or (2) the corrections expanded random noise in the raw profile and did not actually improve the profile. Based upon a comparison of the MST data with the logs, we are convinced that the corrections remove real noise from the raw natural gamma activity data.

Figure 6 shows a section of NGT (natural gamma ray activity tool) logging data from the density logging run at Hole 911A. This data set is compared to the corrected MST data from the same interval, chosen because both data sets were reasonably complete over the depth range. Both data sets were "cleaned": for the MST data, no data with an average dry bulk density less than $0.6 \mathrm{~g} / \mathrm{cm}^{3}$ is plotted, because such low dry bulk density values are evidence for significant amounts of void space and large amounts of applied correction. Similarly, the logging data were stripped of intervals where the hole width was greater than 16.5 inches $(41.9 \mathrm{~cm})$, near the maximum width of the caliper measuring device on the HLDT (high temperature lithodensity tool).

The profiles in Figure 6 are similar to each other, although there are obviously some differences, too. The well logging data has been depth-shifted by $-2.3 \mathrm{~m}$ (a depth of $100 \mathrm{~m}$ has become $97.7 \mathrm{~m}$ ) to best match the upper section of core data. This depth shift compensates for the slight offset caused by measuring the depth of the hole with two different measuring devices. The MST depth data are measured with the drill string, while the well logging depth is measured by the length of logging wire out. Other offsets between the MST and logging data are probably caused by incomplete recovery of cores. A close examination of Figure 6 shows blank sections on the MST curve beginning about 100 mbsf. In each case these cores did not recover a full $9.5 \mathrm{~m}$, but only partially sampled the cored interval. ODP policy marks core depths to begin at the shallowest part of the cored interval. If the sediment were recovered from another part of the interval there can be a significant offset between logging and core records. A significant part 


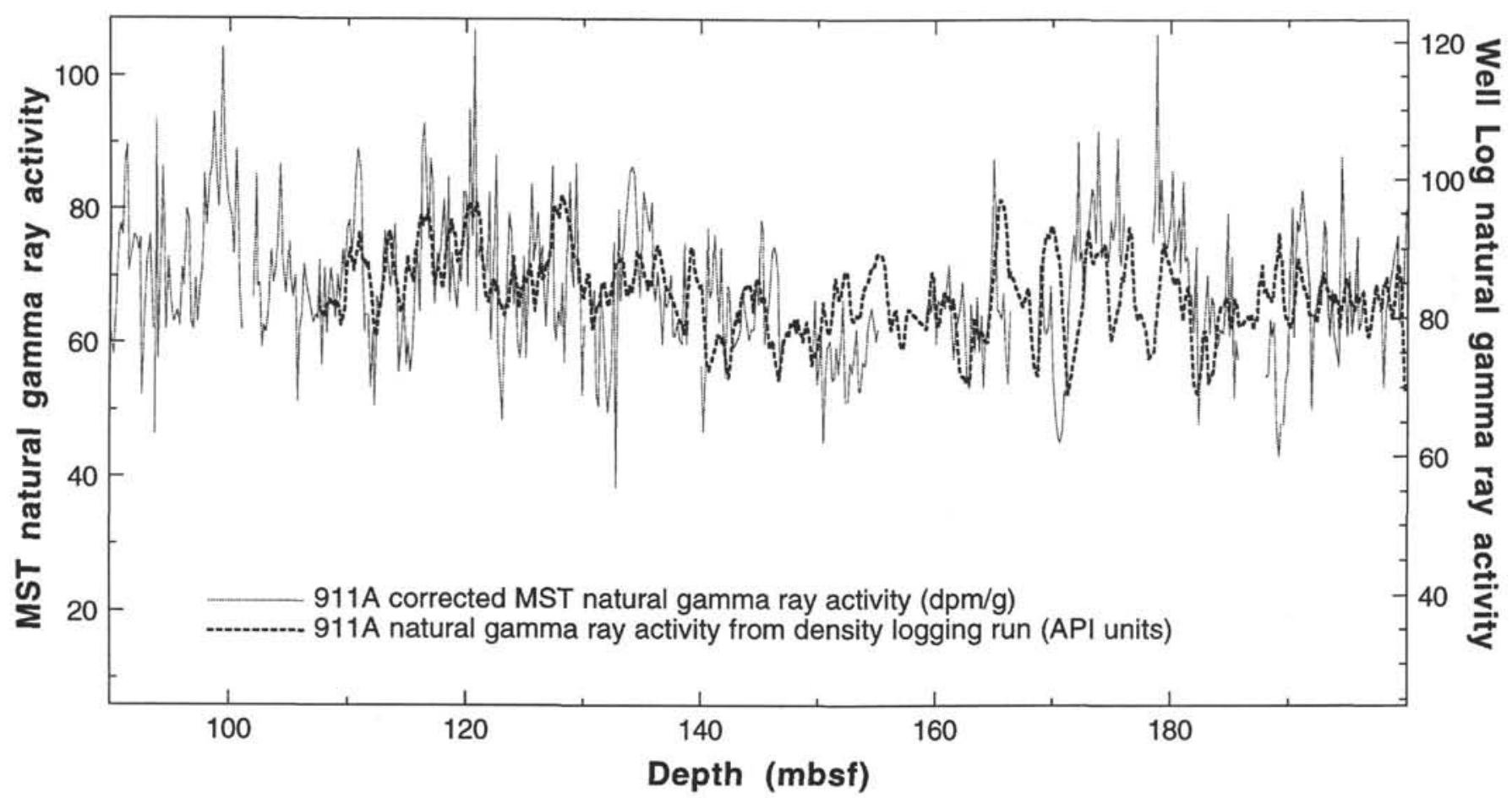

Figure 6. A comparison of the cleaned and corrected MST natural gamma ray activity profile at Hole 911A to that collected during the density logging run, for the interval between 90 and $200 \mathrm{~m}$. While minor offsets can be observed for some core intervals, the profiles are for the most part similar.

of the mismatch between 140 and 180 mbsf may be due to these shifts. Despite these discrepancies, the match between the log and the MST data is very good, and suggests that the corrections to the MST data are well founded.

We make a further comparison of MST and logging data at Hole 908A (Fig. 7), because the variability in natural gamma ray activity is greater there, and it thus provides a second opportunity to evaluate the corrections to the MST data. In addition, there were few voids in this core, reducing the need for one of the major correction steps to the MST data. The MST data in Figure 7 were depth-shifted by +2.5 $\mathrm{m}$ below $175 \mathrm{~m}$, but otherwise there has been no adjustment to the profiles. The MST and logging natural gamma ray activity curves are very comparable here, as they were at Site 911, except for some spikes that appear in the logging data below $170 \mathrm{mbsf}$ which are not found in the MST data. The borehole in this interval was partly washed and partly swelling shut, which adversely affected the quality of the logging data.

These two examples indicate that the corrections made to the MST natural gamma ray activity were needed and improve the quality of the MST data. While hole conditions and core conditions proved to be difficult at Site 911, a good match can be made between core and logging data.

\section{EVALUATION OF MST DATA FOR MEASURING K ACTIVITY IN CLAYS}

Besides measuring total natural gamma ray activity, the MST natural gamma ray detector also measures activity in energy windows designed to detect gamma rays specifically emitted from $\mathrm{K}, \mathrm{U}$, and Th. Here we evaluate how well these data can be used to measure these elements in Site 911 sediments. We only have elemental data from shipboard XRF measurements of major element composition (Shipboard Scientific Party, 1995; p. 287) and thus can only compare potassium measurements by XRF to the MST data. This, however, should give some measure of the sensitivity of the MST for elemental analysis.

On Leg 151, Window 3 of the MST detector was set up to collect gamma rays in the energy range between 1.104 and $1.614 \mathrm{MeV}$. The $\mathrm{K}$ gamma ray energy is near the center of this range, at $1.46 \mathrm{MeV}$. The counts measured in this energy window not only include the ship's background radioactivity but also enhanced background activity from scattered gamma rays from higher energy $U$ and $T h$ daughters. The raw counts must be corrected for both of these effects. The shipboard background measurement in Window 3 was 0.45 counts/ sec. This background was measured in the same way as the background for the total natural gamma activity: an empty tray was placed in the detector and repeated background measurements were made. The background for $\mathrm{U}$ and Th was made after we noted that high counts were visible in Window 3 when we measured $U$ and Th standards. We corrected for these background counts by subtracting 0.03 times the measured counts in Window 1. After these background corrections were made, the raw counts were corrected and calibrated in the same manner that total natural gamma ray activity had been corrected and calibrated earlier.

Thirty-two XRF samples were analyzed for major elements in Hole 911A. Of these samples, nine were sufficiently near voids to make the MST natural gamma ray data suspect. Thus, a total of 23 samples were used to compare MST and XRF data. The $\mathrm{K}_{2} \mathrm{O}$ contents of these samples were compared to the corrected Window 3 data, and this comparison is shown in Figure 8. We observed no significant correlation between the two data sets. We checked to see if the corrections could have reduced the correlation between measured potassium and Window 3 gamma ray activity, but found no correlation between either the raw counts or the counts corrected only for shipboard background and the XRF-measured potassium.

The lack of any correlation between these two potassium measurements shows that the MST detector is insufficiently sensitive to 


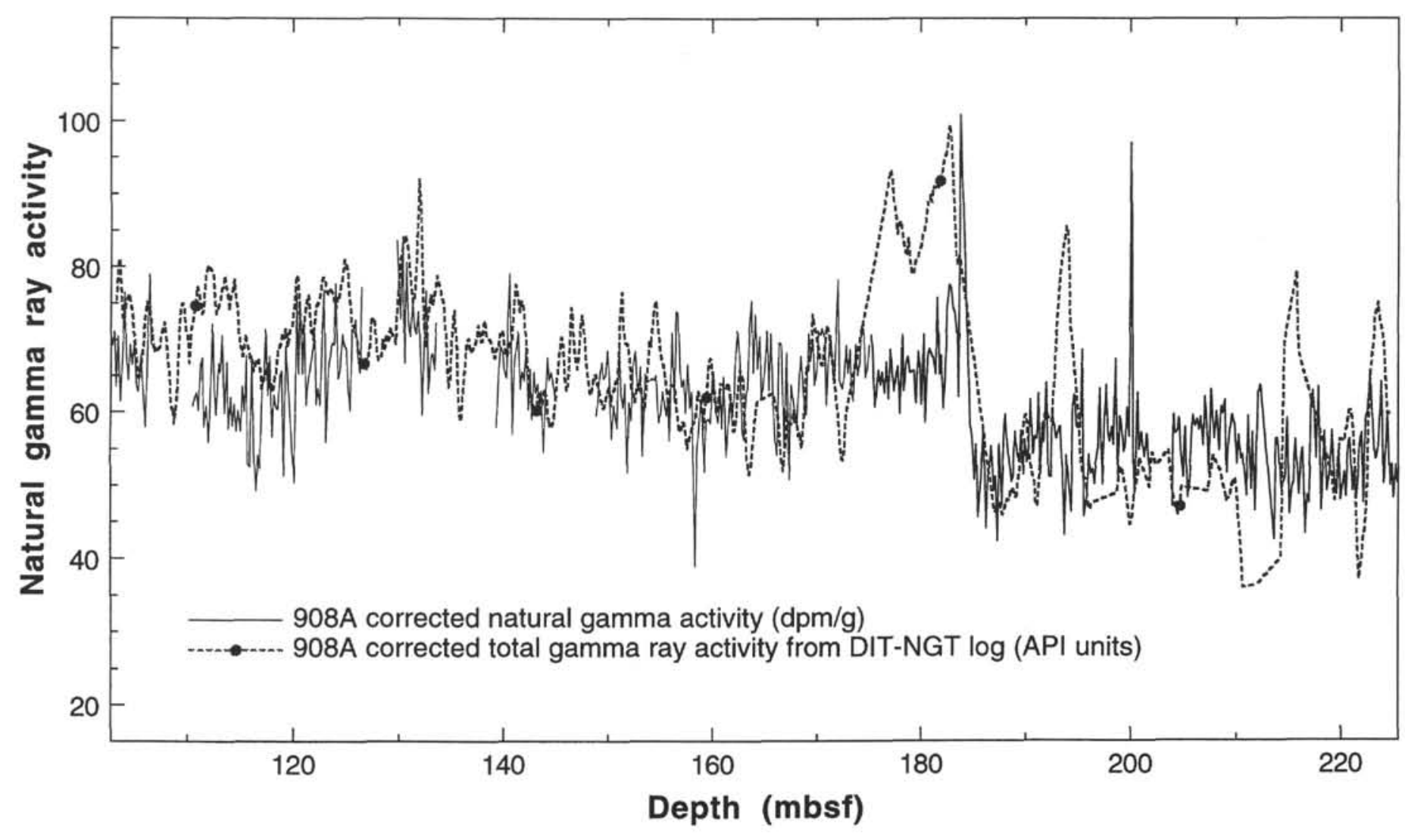

Figure 7. Comparison of corrected MST and logging natural gamma ray activity data, at Hole 908A. In this case, because the void problem was not as severe, no special cleaning of the data was needed. Again, the match between corrected MST data and the logs is very good.

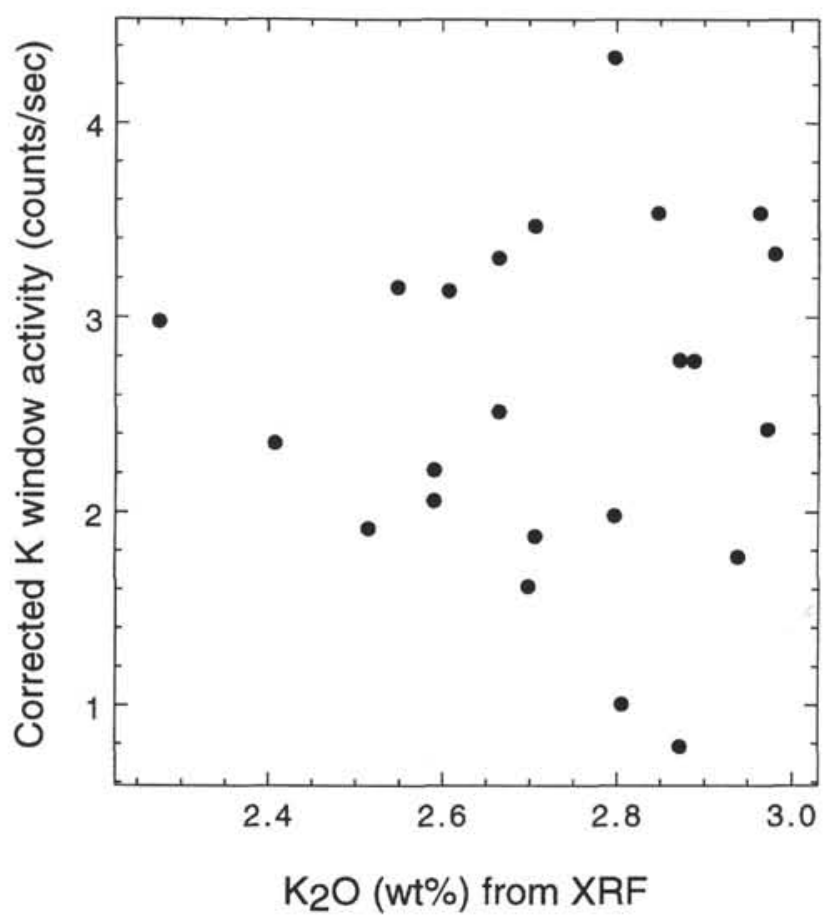

Figure 8. Scatterplot of $\mathrm{K}_{2} \mathrm{O}$ measured in Hole 911A to corrected counts in the MST energy window for $\mathrm{K}$ (Window 3 ). There is no more than a vague positive correlation observable in the data. The MST natural gamma ray detector does not appear sensitive enough to measure potassium to a precision better than $\sim 1 \%$. measure the small range of potassium variation at Site 911 . Since the range in potassium contents at the site was approximately $0.8 \mathrm{wt} \%$ $\mathrm{K}_{2} \mathrm{O}(\sim 0.65 \%$ elemental $\mathrm{K})$, we believe that only differences in $\mathrm{K}$ greater than about $1 \%$ may be detectable by the MST. Further comparisons with other lithologies are needed to improve this estimate of sensitivity.

\section{DEPTH ADJUSTMENTS TO HOLE 911A CORES BASED UPON WELL LOGGING DATA}

One objective of this study was to construct a better composite natural gamma ray activity profile for Site 911 . This objective has been frustrated to a great extent by hole conditions at Site 911. Piston coring could only penetrate to $139 \mathrm{mbsf}$ in Hole $911 \mathrm{~A}$ and $112 \mathrm{mbsf}$ in Hole 911B. Open-hole logging and good logging profiles of natural gamma ray activity only occurred below $117 \mathrm{mbsf}$, however, because the conical sidewall entry sub was attached to the drill pipe to allow pipe movement while logging to break through bridges forming in the hole. Overlap between APC-cored sections and logging data was minimal (about $20 \mathrm{~m}$ ). In the XCB section, significant core gaps make it difficult to match core sections to the logs.

Nevertheless, there is sufficient similarity between the logging data and the corrected MST data (Fig. 6) to adjust core depths by comparing MST and well-logging data. Cores can be depth-shifted to a depth of about $320 \mathrm{~m}$, at which depth major features are found in the NGT natural gamma ray activity logs that cannot be found in the core data (Fig. 9). We believe that the mismatch below this level is probably caused by data artifacts from hole conditions within the logging data. Removal of these may be difficult or impossible.

While it will be difficult to build a composite section to the base of Site 911 , we can make one to a depth of about $320 \mathrm{mbsf}$, which is 


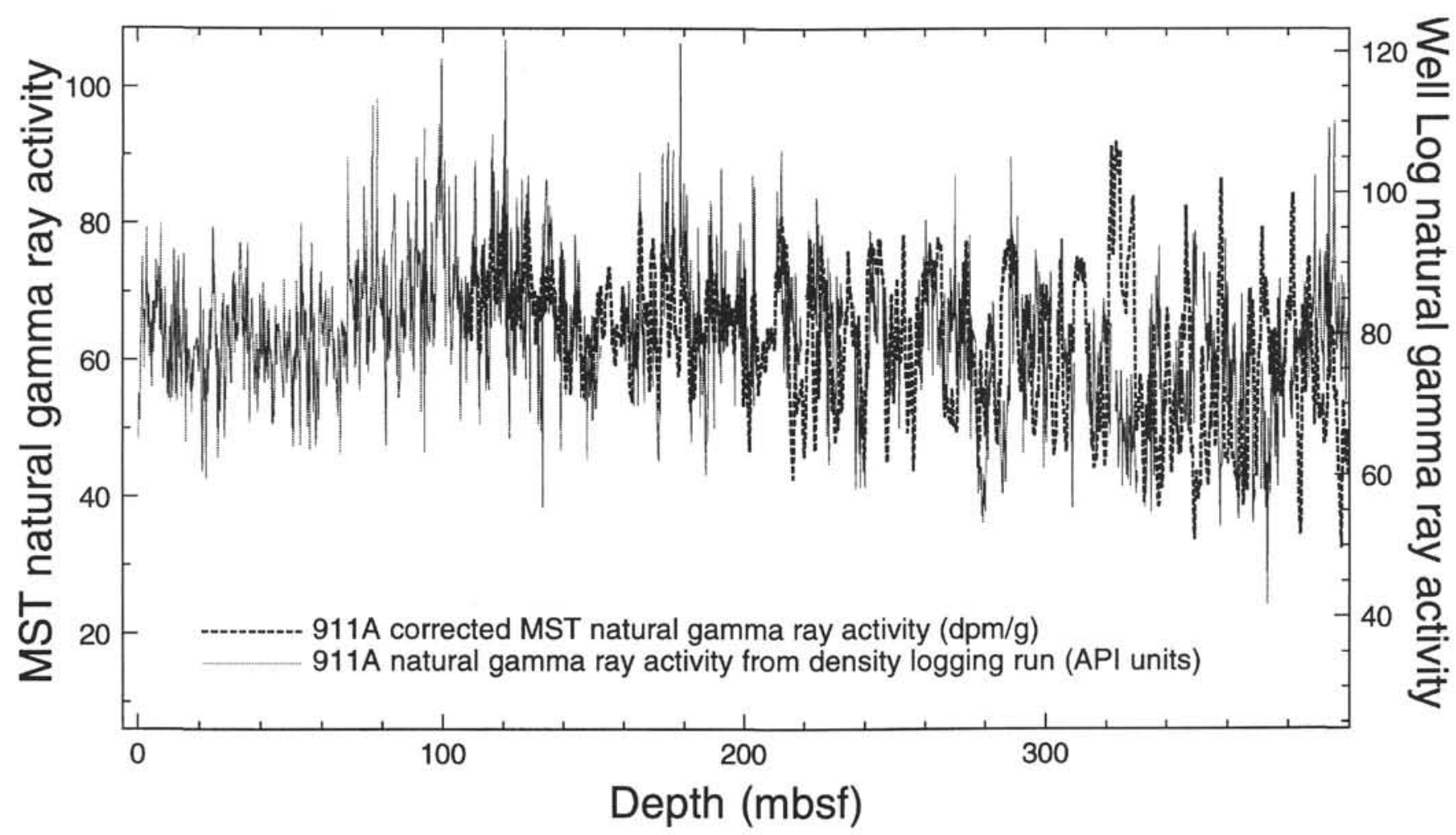

Figure 9. A comparison of depth-shifted MST natural gamma ray activity and NGT logging data for Hole 911A. The match between the two data sets is excellent between the start of the logging data set at about $110 \mathrm{mbsf}$ and about $320 \mathrm{mbsf}$. Below this depth there appear to be significant artifacts in the logging data as well as significant gaps in the recovered core.

Table 1. Depth adjustments to Hole 911A cores by comparison to well logging natural gamma ray activity.

\begin{tabular}{cc}
\hline Core number & $\begin{array}{c}\text { Depth shift } \\
(\mathrm{m}) *\end{array}$ \\
\hline $13 \mathrm{H}$ & +0.0 \\
$14 \mathrm{H}$ & -1.0 \\
$15 \mathrm{H}$ & +0.3 \\
$16 \mathrm{X}$ & -1.3 \\
$17 \mathrm{X}$ & -2.8 \\
$18 \mathrm{X}$ & +0.5 \\
$19 \mathrm{X}$ & +0.9 \\
$20 \mathrm{X}$ & +0.0 \\
$21 \mathrm{X}$ & -2.0 \\
$22 \mathrm{X}$ & -1.1 \\
$23 \mathrm{X}$ & +3.5 \\
$24 \mathrm{X}$ & +1.8 \\
$25 \mathrm{X}$ & +2.2 \\
$26 \mathrm{X}$ & +0.0 \\
$27 \mathrm{X}$ & +0.0 \\
$28 \mathrm{X}$ & +2.0 \\
\hline
\end{tabular}

Note: *Depth shift is added to core depth reported by the Shipboard Scientific Party (1995) to get the corrected depth.

about $200 \mathrm{~m}$ longer than the composite which can be constructed from APC/XCB data alone. Table 1 lists depth shifts we have identified for Cores $911 \mathrm{~A}-13 \mathrm{H}-28 \mathrm{X}$, and which are used when displaying shifted MST profiles. Figure 10 shows a detail of the section between about 135 and 270 mbsf. There are significant gaps in the cored section throughout this interval. While general trends appear in both the logging and core MST data, it is also fairly obvious that mismatches occur between the two in the unshifted data. In contrast, minor depth shifts for cored intervals produce a very good match to the logging data (Fig. 10, bottom). Thus, we can identify gaps in the cored section and establish much better depth control through the combined use of MST core data and logs from the drillhole.

\section{CONCLUSIONS}

The newly installed natural gamma ray activity sensor will collect a useful new data set for study of ODP cores. The raw data from this sensor needs significant corrections, however, before it can be compared with logging natural gamma ray activity data or used to study lithology. Logging data, in turn, may have significant artifacts from poor hole conditions that may make it difficult to match MST and logging profiles. Nevertheless, we were able to construct a composite section of MST and logging data in an XCB interval of moderate recovery in Hole $911 \mathrm{~A}$ between about 120 and $320 \mathrm{mbsf}$. The length of missing section between recovered core could then be reliably determined.

We also attempted to calibrate the MST natural gamma activity sensor to measure $\mathrm{K}$ in Site 911 cores, but failed to get any useful correlation between gamma activity from the $\mathrm{K}$ gamma energy window and measured $\mathrm{K}_{2} \mathrm{O}$ by shipboard XRF. Because the $\mathrm{K}$ contents of these sediments were relatively constant (between 2.2 and $3.0 \mathrm{wt} \%$ ), we believe that the variation of $\mathrm{K}$ contents downcore was less than the detector sensitivity. In its present configuration, we estimate the detector sensitivity to be about $1 \%$ for $\mathrm{K}$.

\section{REFERENCES}

Heier, K.S., 1969. Potassium-isotopes in nature. In Wedepohl, K.H. (Ed.), Handbook of Geochemistry (Vol II-1): New York (Springer-Verlag), 19B-1-19-B-2.

Hoppie, B.W., Blum, P., and the Shipboard Scientific Party, 1994. Natural gamma-ray measurements on ODP cores: introduction to procedures with examples from Leg 150. In Mountain, G.S., Miller, K.G., Blum, P., et al., Proc. ODP, Init. Repts., 150: College Station, TX (Ocean Drilling Program), 51-59.

Keys, W.S., and MacCary, L.M., 1971. Application of borehole geophysics to water-resources investigations. In Techniques of Water-Resources 
Investigations of the United States Geological Survey (Book 2): Collection of Environmental Data: Washington (U.S. Govt. Printing Office).

Shipboard Scientific Party, 1995. Site 911. In Myhre, A.M., Thiede, J., Firth, J.V., et al., Proc. ODP, Init. Repts., 151: College Station, TX (Ocean Drilling Program), 271-318.
Date of initial receipt: 6 July 1995 Date of acceptance: 2 February 1996 Ms 151SR-125
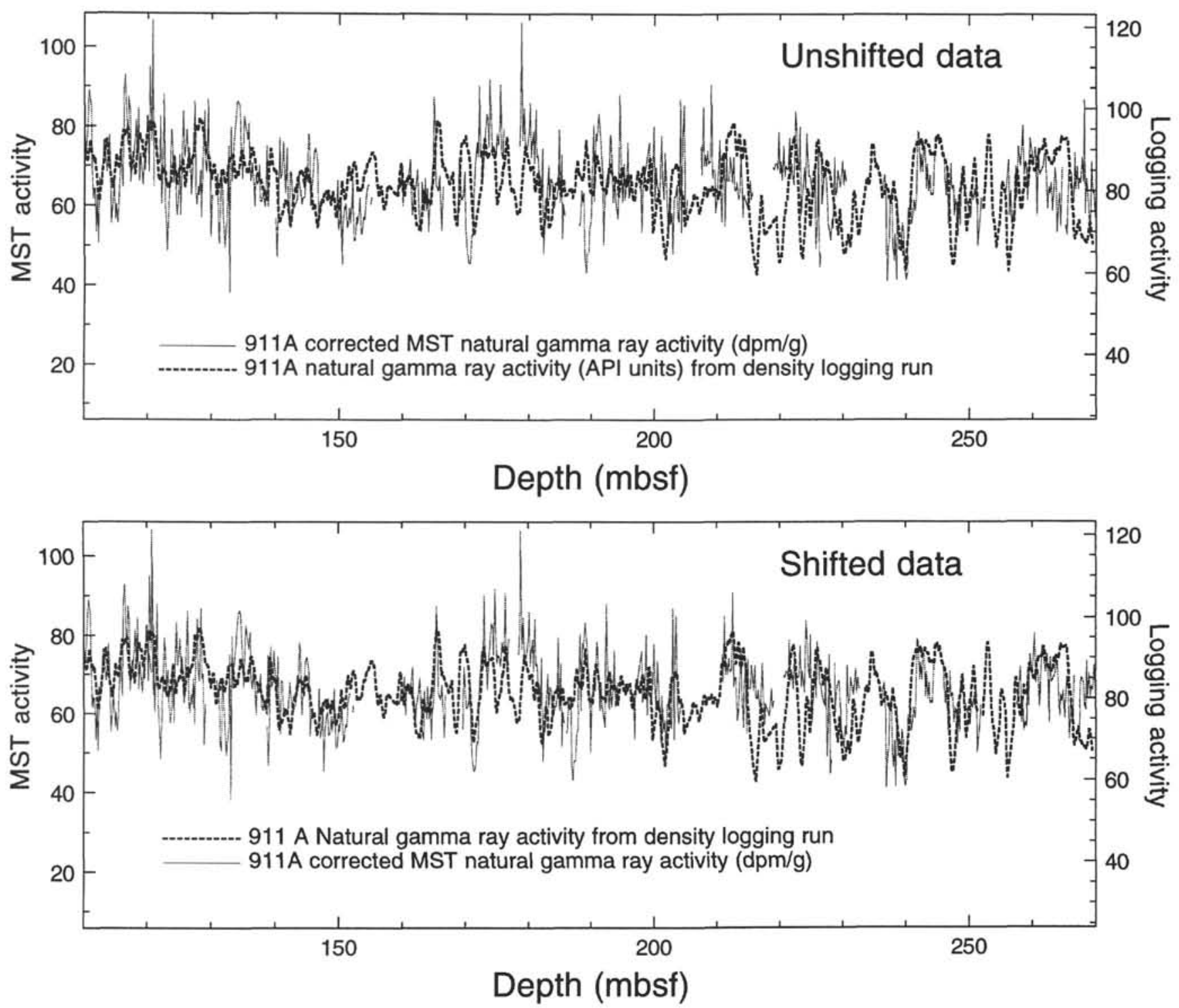

Figure 10. A detailed comparison of original and depth-shifted MST natural gamma activity data with the NGT logging data. Most of the depth shifts were minor except near 220 mbsf. Coherence between NGT and MST data improves significantly with the depth-shifting. 